\title{
AMPLIAÇÃO DA DISTRIBUIÇÃO GEOGRÁFICA DE PHONEUTRIA BAHIENSIS SIMÓ \& BRESCOVIT, 2001 (CTENIDAE: CTENINAE) NO ESTADO DA BAHIA, BRASIL
}

\author{
Marcelo Alves Dias ${ }^{1}$; Kátia Regina Benati² \& Marcelo Cesar Lima Peres $^{2}$
}

Biota Neotropica v5 (n1a) http://www.biotaneotropica.org.br/v5n1a/pt/abstract?short-communication+bn013051a2005

Recebido em 07/12/2003

Publicado em 01/02/2005

${ }^{1}$ Rua Rio São Francisco, 60, CIA-1, 43700-000, Simões Filho, Bahia, Brasil. E-mail: biolmadias@hotmail.com ${ }^{2}$ Universidade Católica do Salvador, Instituto de Ciências Biológicas, Centro de Ecologia e Conservação Animal (ECOA), Av. Prof ${ }^{\circ}$ Pinto de Aguiar, 2589, Pituaçu, 41740-090, Salvador, Bahia, Brasil.

\begin{abstract}
Four specimens of Phoneutria bahiensis Simó \& Brescovit 2001 were identified amongst material of a faunal rescue carried out in Itapebi county, southern Bahia. This record enhances the geographic distribution of the species, since to date, the literature restricts the occurrence of P. bahiensis only to the city of Ilhéus and Salvador.
\end{abstract}

Key words: Phoneutria bahiensis, geographic distribution, Bahia.

\section{Resumo}

Foram identificados quatro espécimes de $P$. bahiensis, decorrentes de um resgate de fauna realizado no município de Itapebi, extremo sul da Bahia. Este registro amplia a distribuição geográfica da espécie, visto que a literatura, até o momento, restringia a ocorrência da $P$. bahiensis apenas às cidades de Ilhéus, no sul da Bahia e Salvador.

Palavras-chave: Phoneutria bahiensis, distribuição geográfica, Bahia.

http://www.biotaneotropica.org.br 


\section{Introdução}

O gênero Phoneutria (Perty 1833) tem ampla distribuição na região tropical, no Brasil ocorre em todas as regiões. São consideradas aranhas de importância médica e recentemente foi descrita uma nova espécie, Phoneutria bahiensis, endêmica do estado da Bahia (Simó \& Brescovit 2001).

Sua restrita distribuição, associado ao baixo número de exemplares registrados viabilizou sua inclusão na nova lista das espécies da fauna brasileira ameaçadas de extinção (Ministério do Meio Ambiente 2003). Apesar de endêmica sua ocorrência limitava-se a apenas dois registros, um para a cidade de Ilhéus e outro para a cidade de Salvador. O objetivo deste trabalho foi registrar uma nova ocorrência de $P$. bahiensis para o estado da Bahia.

\section{Material e Métodos}

O material examinado constou de dois machos e duas fêmeas que estão depositados na coleção científica do Centro de Ecologia e Conservação Animal -ECOA/ICB/UCSal. Para a identificação utilizou-se a chave de classificação taxonômica proposta por Simó \& Brescovit (2001).
Os animais examinados provieram de um resgate de

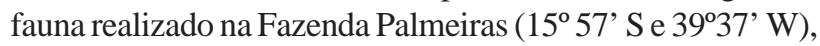
trecho representativo de mata que foi atingido com o enchimento da barragem hidrelétrica Itapebi Geração de Energia S.A., no extremo sul da Bahia, na região do município de Itapebi (Figura 1). A região apresenta altitude aproximada de 177 m, domínio fitogeográfico de Mata Atlântica, fragmentada por amplas áreas de pastagem.

\section{Resultados e Discussão}

Foram identificados quatro espécimes de $P$. bahiensis, sendo dois machos e duas fêmeas. Este registro amplia a distribuição geográfica da espécie, visto que a literatura, até o momento, restringe a ocorrência da $P$. bahiensis apenas às cidades de Ilhéus, no sul da Bahia e Salvador (Simó \& Brescovit 2001).

As cidades localizadas na região sul do estado, distanciam-se uma da outra em $131 \mathrm{~km}$, o que comprova o aumento do raio de ocorrência da espécie em estudo.

Em Ilhéus o local de ocorrência foi uma formação vegetal caracterizada pela plantação de cacau em sistema de cabruca. No município de Salvador o espécime foi encontrado

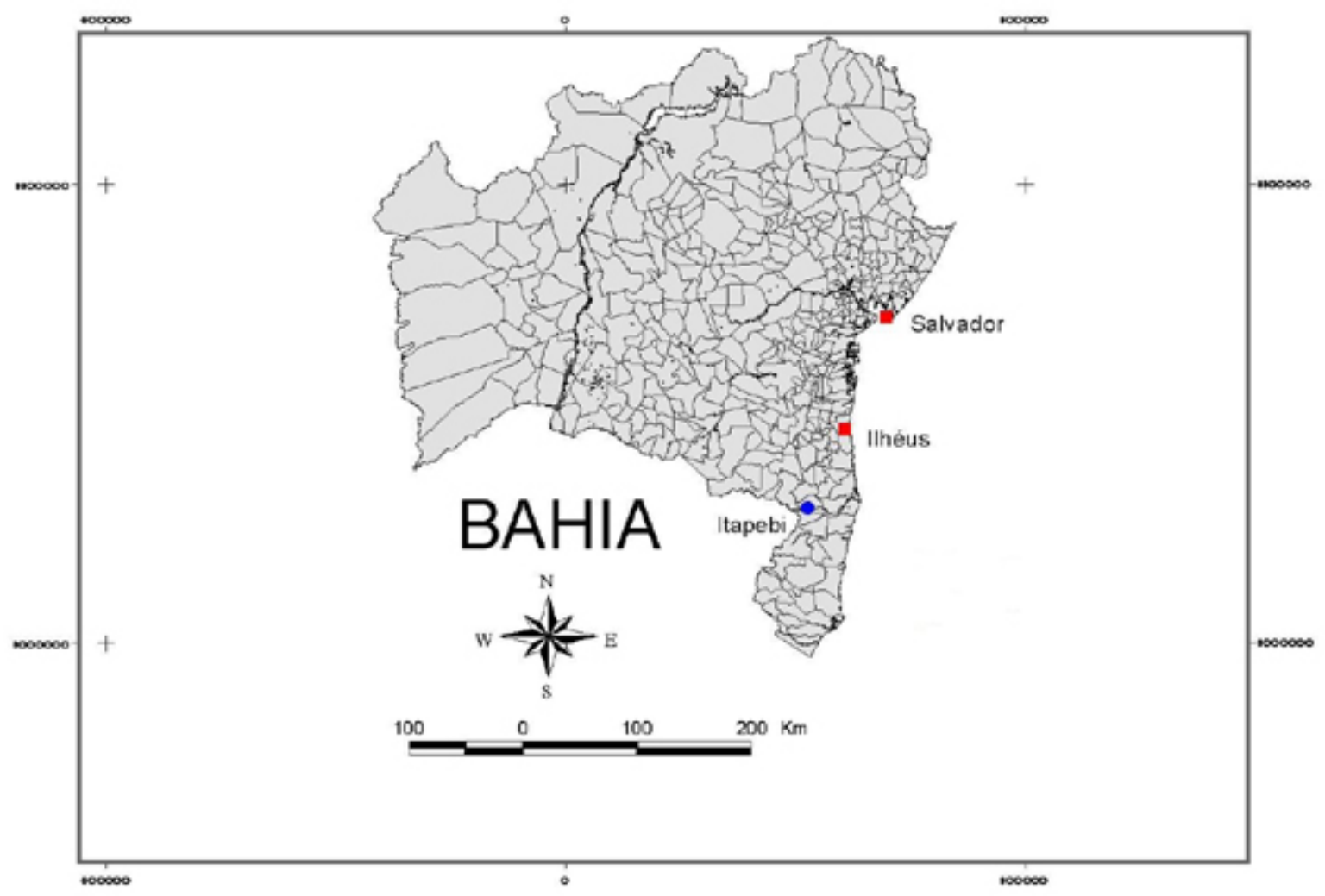

Figura 1: Mapa do Estado da Bahia assinalando a distribuição geográfica da Phoneutria bahiensis (Simó \& Brescovit 2001) nos municípios de Ilhéus e Salvador e novo registro na cidade de Itapebi.

http://www.biotaneotropica.org.br 
num ambiente de restinga na Área de Proteção Ambiental Lagoas e Dunas do Abaeté. A região de nova ocorrência, no município de Itapebi, compreende uma área de floresta ombrófila densa, demonstrando assim a diversidade de ambientes com registros para essa espécie.

A associação dessa espécie com a ocorrência de acidentes de araneísmo no Brasil e seu novo registro, sugerem que sejam feitas amostragens direcionadas a captura destes indivíduos, a fim de fornecer dados mais precisos sobre a sua distribuição geográfica e se realmente esta espécie corre risco de extinção.

\section{Agradecimentos}

Ao colega Ângelo Giussepe Rodrigues Brasileiro pela doação dos animais. Ao Dr. Antonio D. Brescovit (Instituto Butantan) pelo auxílio na identificação taxonômica e registros fotográficos. Aos colegas Moacir Tinôco e Manoel Michael Meirelles Sena (Centro ECOA/UCSal) pelas sugestões e revisão do manuscrito. A colega Alina Sá Nunes pela confecção do mapa.

\section{Referências Bibliográficas}

MINISTÉRIO DO MEIO AMBIENTE. 2003. Lista Nacional das Espécies da Fauna Brasileira Ameaçada de Extinção, Brasil (on line) - Disponível em: http:// www.mma.gov.br/ port/sbf/fauna/index.cfm. Acesso: 28/11/2003.

PERTY, M. 1833. Brasilianische Spinnen. In J. B. de Spix \& F. F. Martius, Delectus Animalium Articulatorum quae in itinere per Braziliam ann. 1817 et 1820 colligerunt: 191209. Monachii.

SIMÓ, M. \& BRESCOVIT, A.D. 2001. Revision and cladistic analysis of the Neotropical spider genus Phoneutria Perty, 1833 (Araneae, Ctenidae), with notes on related Cteninae. Bull. Br. Arachnol. Soc. 12(2): 67-82.

Título: Ampliação da distribuição geográfica de Phoneutria bahiensis Simó \& Brescovit, 2001 (Ctenidae: Cteninae) no estado da Bahia.

Autores: Marcelo Alves Dias; Kátia Regina Benati \& Marcelo Cesar Lima Peres

Biota Neotropica, Vol. 5 ( número 1a): 2005

http://www.biotaneotropica.org.br/v5n1a/pt/ abstract?short-communication+bn013051a2005

Recebido em 07/12/2003 - Publicado em 01/02/2005

ISSN 1676-0603

http://www.biotaneotropica.org.br 